\title{
Closing The Gap - Information Systems Curriculum And Changing Global Market
}

Kerry Henson, University of Central Missouri, USA

Mustafa Kamal, University of Central Missouri, USA

\begin{abstract}
The power of outsourcing basic computing technology such as computer programming, database design, customer service operations and system development, to mention a few have changed the conditions of employment in IT. Many of the projects that went off-shore did not perform well due to failure to consider important factors in business dimensions.
\end{abstract}

\section{INTRODUCTION}

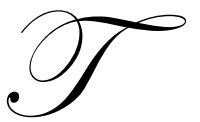

he power of outsourcing basic computing technology such as computer programming, database design, customer service operations and system development, to mention a few have changed the conditions of employment in IT. Many of the projects that went off-shore did not perform well due to failure to consider important factors in business dimensions. Although many of these core activities have come back and are here to stay, more and more of the non-core activities such as those mentioned above, among others will continued to be outsourced. Traditional 'computer programming' curriculum based on purely technology and disconnected from business processes will not work in future. Any business entity both in the retail and wholesale sector, whether selling goods including technology or services will tell you that just 'technological' know-how without a broader concept of the business environment do not work anymore [1-4]. The undergraduate Computer Information Systems curricula in the USA that are currently housed in the Business Colleges and accredited by the AACSB [5] require a business core in the degree program. However, a systematic approach to the curriculum development as a business model is needed to stay in-sync with what is needed in the ever changing global environment. The role of an advisory board whose membership comes from a wide range of business practitioners is critical in this curriculum development as well as maintenance processes.

\section{ADVISORY BOARD}

Undergraduate information systems programs provide students with a basic set of skills and knowledge to prepare them to enter the workforce. Many academic departments structure their curriculum based on faculty training, abilities and model curriculum suggested by professional societies. This 'bottom-up' approach assumes that the market has the same static world-view as their faculty and that one cookie-cutter format works for everyone. Comparison of three surveys given to a sample of IT project managers in the Kansas City and St. Louis area in 1999, 2003 and 2007 to find ten most sought after skills in IT graduates show a dramatic shift in the requirements list. While in the 1999 technical skills were the main driver, the nature of skill sets have shifted, over the years, more and more towards business and soft skills. Many of the technical skills that were dominant earlier did not even make the top ten in 2007. The key question, as always, is that what skill sets you are looking for in today's IT graduates in your company and what will change in the next five years? Who can bring to the table this unique perspective, but the business community. We suggest the following approach:

1. Know the employers that hire your graduates; include small, medium as well as large companies / agencies.

2. Include companies that sell technology and that use technology

3. Select one member from each company, maximum of fifteen to twenty.

4. Meet at least once a year. 


\section{CURRICULUM DEVELOPMENT}

Take a top down approach. Computer Information Systems curriculum normally have a business core and a major area. Focus on the major area first. All AACSB accredited program will have a common business core with other business majors.

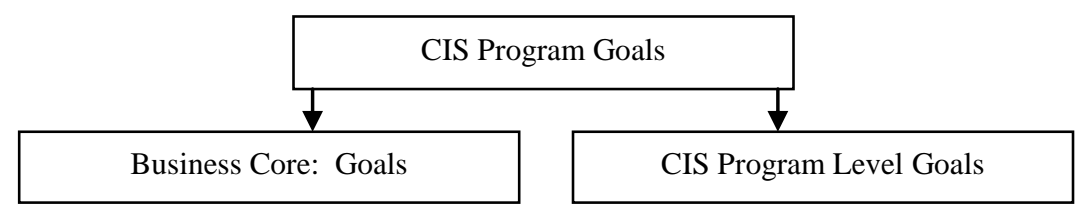

\section{CIS Program Level Goals}

Important question is the following: looking ahead, three to five years from now what are the ten most important CIS (and related business) skill sets will be needed to have an entry level IT job in your company? Please make a list and rank in order of importance, ten being the most important. Here is a sample average from twenty different companies that include small, medium and large companies:

\begin{tabular}{llc} 
& \multicolumn{1}{c}{ Skill sets } & Rank \\
1 & Work ethic (demonstrated) & 8.89 \\
2 & Desire for excellence & 8.56 \\
3 & Testing and executing a plan & 8.56 \\
4 & Working in groups & 8.44 \\
5 & Problem solving skills & 8.20 \\
6 & OOA and D & 8.00 \\
6 & Software engineering analysis, design & 8.00 \\
6 & Software engineering development & 8.00 \\
6 & SQL & 8.00 \\
7 & People skills & 7.90 \\
8 & Facilitation & 7.89 \\
8 & Project management and methodology & 7.89 \\
8 & Project management and methodology & 7.89 \\
8 & Web Development Skills & 7.89 \\
9 & Time management skills & 7.80 \\
10 & Leadership & 7.78 \\
10 & PMI & 7.78
\end{tabular}

The above list reflects the regional market and must be considered. Here is a top-down approach in the curriculum development and update:

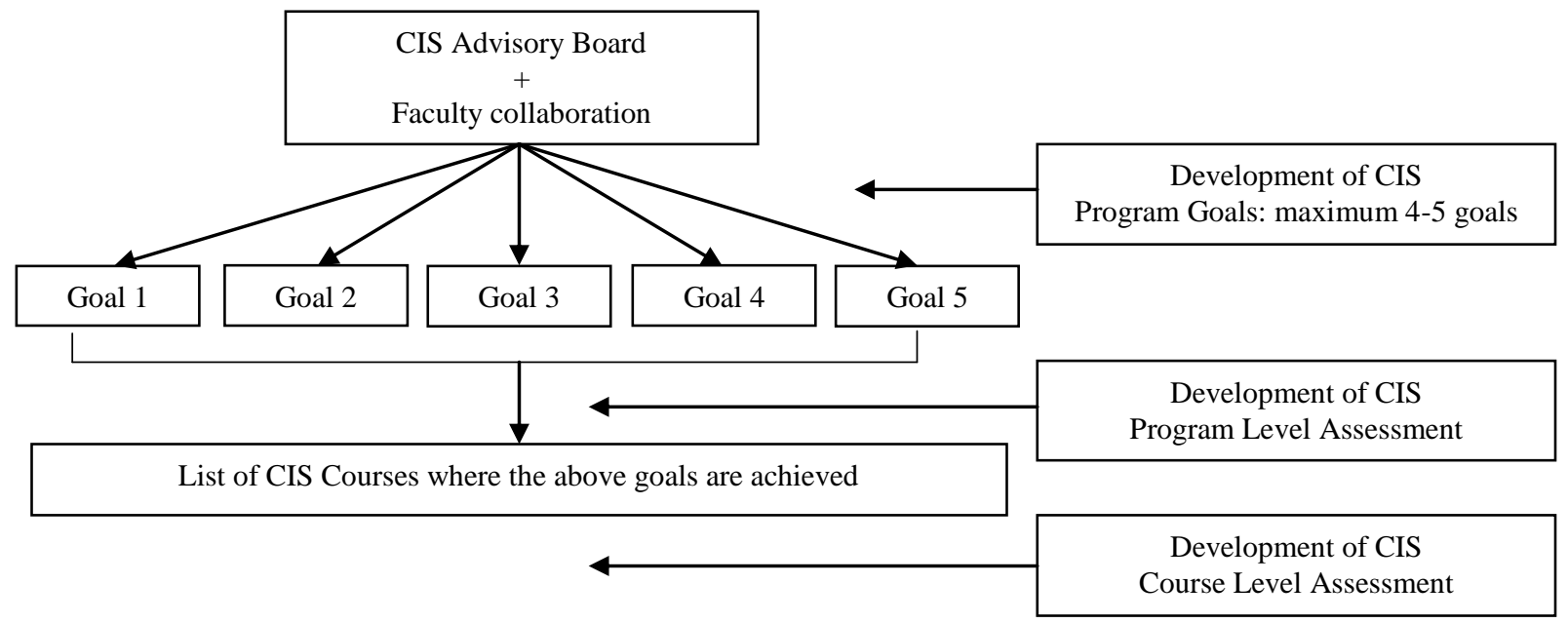




\section{Academic Context: The Program Change}

The CIS Advisory Board at Central Missouri State University consists of invited managers and directors from government agencies and a number of large, medium and small-sized companies within a four-state region. Board participants represent a variety of sectors including telecommunications, software development, utilities, banking, investment advisor, insurance, health care and aircraft industries.

In Spring 2004, prompted by falling enrollments, the CIS Department at University of central Missouri requested the Advisory Board to take a different approach - a need based curriculum approach. Small groups of members representing diverse organizations, were asked to start from scratch, to begin with a blank slate and design a new program based on the industry need. Their initial brainstorming sessions focused on general core capabilities that an entry-level IT employee should possess.

Some of the major themes that emerged include:

- A diverse set of skills and abilities is necessary even at entry-level positions.

- $\quad$ Non-technical abilities continue to be important.

- $\quad$ Must have a rounded, rather than narrow approach to the technical world.

It became evident that general core capabilities should be grouped around three focal points: technical, business and people/personal skills. Comments gleaned from participants are summarized below:

Technical Capabilities:

- $\quad$ Possess a strong technical foundation

- $\quad$ Apply a logical approach to problem solving; Design a coherent solution

- $\quad$ Emphasis on underlying skill sets rather than specific skills/technologies

- $\quad$ End-to-end knowledge-architecture

- $\quad$ Application/system integration

- $\quad$ Data security, network security and risk management

- $\quad$ Database design/administration

- $\quad$ System maintenance

- $\quad$ Troubleshooting of software, hardware and inter-networks

- Understand quality assurance processes, performance and reliability; Be able to develop testable requirements

- $\quad$ Interface design and usability for design of in-house and web applications

Business/Management Capabilities:

- $\quad$ Be able to apply IT to solve real business problems

- $\quad$ An understanding of the business and organizational values

- $\quad$ Must understand and apply project management philosophy in light of needs and constraints; Be able to estimate needed resources for a project

- $\quad$ Be able to perceive a project in the context of the larger business objectives

People/Personal Capabilities:

- $\quad$ Personal maturity and a strong work ethic

- $\quad$ Creativity

- $\quad$ Be flexible and ready to adapt in a dynamic environment

- $\quad$ Excellent communication skills; Be able to relate to the customer; negotiation skills

- $\quad$ Basic marketing skills; Be able to sell their ability to do the job 
- $\quad$ Strong time management skills; Must be able to follow and deliver according to the project plan

- $\quad$ Be able to think "outside the box", be able to handle unstructured problems

- $\quad$ Be able to work under a high level of stress

- $\quad$ Be able to work within a team whether as a team member or leader/member

- $\quad$ Operationally mature and professionally savvy.

\section{KNOWLEDGE/SKILLS ATTRIBUTED TO BUSINESS COURSES}

As described above, there were a number of core capabilities classified as either business/ management or people/ personal. All CIS majors take a 37 hour business core and many of these knowledge/skills are addressed there. CIS faculty, however, emphasized that these issues must be incorporated and practiced within CIS courses. Feedback on presentations will help verbal and non-verbal communication skills. Working within groups helps students enhance their teamwork, cooperation and leadership skills. Emphasis on supply chain and general architecture of major functional systems was increased in the Management Information Systems course.

Students also see much more flexibility in the new program structure. Selecting tracks and the greater number of electives allows the students to better tailor their degree plan to their interests and the direction of perceived employment opportunities. It is hoped this will also enhance the programs marketability to potential students.

\section{CONCLUSION}

The Advisory Board met again in 2005 and 2007. Members responded enthusiastically to the changes and worked with faculty to fine tune individual course content. It was very affirming to the Department to see positive results from its willingness to embrace change and its hard work in curriculum revision. It was also affirming for the Board members to see their suggestions taken seriously.

As students contemplate their career choices and respond to increased demand for entry-level IT employees, we believe the CIS program offered here is structured to appeal to students and address the needs of potential employers. Because of the cooperative effort with the Advisory Board, this program structure well positions the CIS Department "for the times they are a-changin'."

\section{REFERENCES}

1. Accenture, "Driving High Performance Outsourcing - Best Practices from the Masters", http://www.accenture.com/xdoc/en/services/outsourcing/ps/global/landing_ps.pdf

2. Weidenbaum, Murray, "Outsourcing and American Jobs", June 24, 2004, Page 4.; http://wc.wustl.edu/Breakfast_Programs_Transcripts/Weidenbaum_Outsourcing.pdf

3. Chabrow, Eric, "You Call Yourself A Manager? Well, You're Not Alone", Information Week, Jan 16, 2006. http://www.informationweek.com/stroy/showArticle.jhtml?articleID=177100274

4. Chabrow,Eric, "IT Employment reaches record High", Information Week, April 18, 2006 http://www.informationweek.com/showArticle.jhtml;jsessionid=LPW3CMEYOPXPGQSNDBOCKICCJU

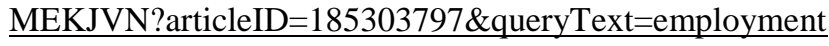

5. http://www.aacsb.edu/ 